\title{
BABY STEPS WITH BIM - LEARNING TO WALK THE TALK
}

\author{
Kathryn Davies ${ }^{1}$, Suzanne Wilkinson ${ }^{2}$, and Dermott McMeel ${ }^{3}$
}

\begin{abstract}
Although there is a great deal of enthusiasm reported for companies to adopt BIM for improved project outcomes and industry productivity, the process of developing BIM expertise is not always an easy one. Project teams frequently come together with a very wide range of knowledge and differing levels of enthusiasm for taking on a BIM 'experiment'. This paper details the BIM implementation process on two New Zealand projects undertaking BIM with largely inexperienced teams. Interviews were carried out with practitioners involved in the projects, who were largely "BIM positive". Their narratives present an optimistic view of the BIM intentions, while still being realistic about problems that emerged. Issues for future consideration are identified. Most revolve around team communication factors and the importance of open and constructive relationships with all parties.
\end{abstract}

Keywords: BIM, adoption, implementation, case study.

\section{INTRODUCTION}

BIM uptake is increasing rapidly worldwide, according to the many surveys carried out in both local and international markets. Predicted uptake in the next few years is high, with near-universal BIM use in the UK expected within 5 years (NBS 2016). In North America, BIM adoption increased from 28\% to 71\% between 2007 and 2012, (McGraw Hill Construction 2012). In New Zealand, a longitudinal study monitoring 43 companies found that all of the companies had used BIM to some extent in 2016, an increase from $85 \%$ in 2015 (EBOSS 2016). Furthermore, the surveys have observed that BIM is now being adopted in a more diverse range of countries (NBS 2016).

The commentary about BIM uptake tends to focus on larger and more established companies leading the innovation, assuming that their momentum within the industry will draw smaller and less technologically advanced companies along in their wake. This has taken place to some degree, but not nearly to the level required to ensure saturation of the industry. Many companies, particularly smaller organisations, are deterred by the barriers and are still unsure of the benefits of moving to BIM, and may be afraid of being 'taken in' by the hype of the BIM movement (Dainty et al 2015). In addition, research often presents the leading edge of BIM adoption, and documents the achievements and benefits that those at the front of the charge stand to gain. This is not particularly useful to those who have yet to move into the simplest BIM processes, and may in fact serve to daunt them because the perceived gap between their current practice and that illustrated in the research appears so large (Davies and Harty 2013). As described by Fox (2014), much of the framing

1 Lecturer, Building Construction and Services, Unitec Institute of Technology, Auckland, New Zealand, kdavies@unitec.ac.nz

2 Professor, Department of Civil and Environmental Engineering, The University of Auckland, Auckland, New Zealand, s.wilkinson@auckland.ac.nz

3 Lecturer, School of Architecture and Planning, The University of Auckland, Auckland, New Zealand, d.mcmeel@auckland.ac.nz Professor, Department of Civil and Environmental Engineering, The University of Auckland, Auckland, New Zealand, s.wilkinson@auckland.ac.nz 
of BIM and the innovation it brings to the construction industry presents only a selective view of the changes and resulting benefits that are occurring in the industry. Some scepticism results: that the hype may not measure up to the reality; that BIM may be only appropriate for large, technologically advanced companies; that it may only be suitable for the large flagship projects that are often presented as case studies. Further questions such as those raised by Smits et al (2016) about whether there is measurable benefit to be gained from BIM adoption illustrate further the complexity of the argument.

\section{CASE STUDIES}

\subsection{Case study approach}

This paper documents two case study projects in Auckland, New Zealand, as a focus to explore the development of BIM processes within a wider industry framework. The first project team have some previous experience in the BIM process and are moving to a more complete BIM implementation. The second case follows a project team who are just beginning to explore BIM in a project framework.

Data came predominantly from qualitative interviews with project participants. Representatives from each of the projects (see Table 1) were individually interviewed for 45-90 minutes each. Interviews were loosely structured and participant-led, following a narrative approach that covered the range of issues identified by the interviewer, but in the sequence and depth that followed the interests or concerns of the interviewee. Topics covered included roles, relationships, documentation and project administration processes, BIM skills, knowledge and training, reporting and accountability, preferences and predictions for BIM use in the future.

Table 1: Roles of Case Study participants.

\begin{tabular}{ccc}
\hline Participant & Project 1 & Project 2 \\
\hline Client - capital works & & $\mathrm{x}$ \\
Client - operations & $\mathrm{x}$ & $\mathrm{x}$ \\
Project architect & $\mathrm{x}$ & $\mathrm{x}$ \\
Architect's BIM manager & $\mathrm{x}$ & \\
Architect's modeller & & $\mathrm{x}$ \\
Services engineer & $\mathrm{x}$ & $\mathrm{x}$ \\
Construction site manager & $\mathrm{x}$ & $\mathrm{x}$ \\
\hline Construction BIM manager & & \\
\hline
\end{tabular}

The case studies are intended to be illustrative rather than representative, and the goal of this paper is to identify and describe experiences and opinions within a developing BIM environment. Quotes have been used to express the various perspectives about BIM within the two project teams, and a wide variety of attitudes and knowledge is evident. 


\subsection{Case Study 1}

Project 1 followed a previous project for the same client and largely the same project team which used a partial-BIM process. All of the parties involved had found value in their initial exploration of the technology, and as a result the client requested a more complete BIM implementation with the expectation that further benefits could be realised. The client had no interest in using BIM for facilities or asset management, but believed a BIM project would reduce duration and provide a greater degree of certainty on the project. There was also an element of future proofing involved, in that they wanted to have models available should they choose to move to a BIM-based system in the future.

The architectural practice employed on the project use Revit modelling in the majority of their projects, and have an experienced BIM manager to assist and direct on BIM implementation. Model exchange and coordination takes place as a matter of course. Despite the established BIM processes in the practice, the project architect was quite ambivalent about the use of BIM in the design process, and expressed concern about its value to the designer. His contention was that there was little advantage gained by, or even disadvantage accruing to, the architect when working in a BIM environment, but potentially great benefit for the construction team, and the main contractor in particular. The BIM manager for the architectural practice was more convinced of the potential value of BIM to the architect and the project as a whole, but did not feel that it was currently being realised. He was quite critical of the client's approach, and felt that the architect was currently the main party determining the level of BIM use on the project.

The main contractor for the project was investing heavily in BIM technology and expertise at the time the project started. The contractor's site manager was positive about the benefits of BIM, although his office was still heavily paper-based. BIM uses were predominantly based on visualisation within a 3D model, with some clash detection and coordination with specialist trades. One of the main restrictions on the company's use of BIM, identified by the site manager, was the lack of skilled staff and consequent reliance on third-party modellers to develop models for use in 4D programming and planning.

\subsection{Case Study 2}

The development of Project 2 as a BIM project was instigated by the client's Facilities Management team, who were upgrading their processes with a system developed in-house. They were keen to see how an as-built BIM model could feed into their processes, and regarded this project as a test-bed to allow them to observe and evaluate the value of BIM. During the course of the project, the client's project manager, who was part of the FM team, left the organisation partway through the design stage. He was replaced by a manager from a capital works rather than operational responsibility, who took over the oversight of the project. In the transition, much of the client's focus on BIM was lost.

The architectural practice for the project had a tentative approach to BIM, with only half of the practice using Revit. The team had previous experience with 3D modelling, largely for visualisation and presentation purposes, and were starting to transition to a more extensive BIM process. This was their first project where the entire documentation process was carried out using Revit. Even though they considered themselves to be new to BIM, the architect did not consider the client's expectations to be significantly different from their standard project approach; "We did ask them what exactly do they want us to do, because we said, well what we normally do is we use Revit as a 3-dimensional software. We would normally exchange files with other consultants. That's what we normally do and we asked them, is that what you want? Do you want more than that? Because you can 
go further, of course. They said, no, just do what you normally do, so that's what we're doing" (Architect Project 2)

The project tender was won by a construction company who were actively developing their BIM capabilities at the time. However, they were unaware of the client's intentions to use the final BIM model as a FM resource, and did not receive the BIM brief that had been produced for the design team. The construction team felt that the design BIM model was largely unsuitable for their needs, and developed their own model for the construction stage of the project. Much of their modelling work was outsourced to a third-party modelling company offshore. The construction team used BIM for programming, resource allocation, site planning and Health and Safety inductions, amongst other purposes. 3D and 4D modelling was extensively used to support the contractor's needs.

\section{FINDINGS AND DISCUSSION}

\subsection{BIM understanding and expectations}

The various parties had differing perceptions of the expertise and capabilities of others within the project teams. For example, the clients in these projects saw themselves as driving BIM adoption, and felt that they had a good understanding of the BIM process. However, the architects in both cases considered that the clients were naïve in their perception of BIM, and potential uses and opportunities offered by BIM adoption were not achieved. Similarly, the contractors felt that the standard of the architectural models limited the uses available to the construction team. Criticisms included the level of detail included in the architectural model, as well as the architects' organisation and management of the model. Moreover, the range of uses the model was applied to was quite limited. This was acknowledged by several of the participants, and was justified by reasoning such as that they were developing trust in the system and were still exploring its capabilities. For example, on Project 1, sections of the structure were constructed in a full-scale mock up in order to establish whether they were constructible as designed. A detailed 3D model of the sections had been prepared by the engineers, but the construction team was not prepared to rely on the model for such a crucial element.

The BIM requirements were not explicit in the contractual expectations in either case study. The client team for Case Study 2 produced a BIM brief for the project, but it concerned with technology issues such as establishing common software platforms and exchange formats. In both projects, the BIM capability of the design teams was a consideration in the procurement process, but apart from requiring handover of a 3D model at the end of the design process, the clients' expectations with regards to BIM were not made part of the contractual obligations of the project team.

Rather than a BIM problem, these issues can be seen as flaws in the communication process. As a result of their inexperience with BIM, the parties did not establish clear expectations and handover points at the outset, so each came to the process with different views of what their roles and expected outputs were. In addition, project deliverables were primarily paper-based, with a traditional drawing set as the principal part of the contract documents. This meant that although BIM as used in the production process, the BIM outputs were treated almost as an afterthought by the project teams.

\subsection{BIM expertise and skills development}

The need for staff with BIM skills suitable for implementing a BIM process was a common theme throughout the two case studies. There were two clear strands to this issue. The 
first complaint was the general lack of availability of people skilled in BIM. This limited the value of the BIM process because no one was able to either develop the model for desired simulations or to interrogate the model for more complex analyses. The site manager for Project 1 suggested that his company was being "held to ransom" by third party modellers who were contracted to deliver specialised modelling functions, but did not have sufficient experience to understand what the company needed from the model. Many of those with BIM specialist skills were seen as more focused on the technology than the process, with less understanding of design constraints and construction methodology; "...a real concern, is that you find that a lot of time, too much time gets spent trying to work out how to build the Revit model as opposed to how you would actually build the building." (Architect Project 1)

A related but distinct issue was the interviewees' concerns about their own personal BIM knowledge and capabilities. Apart from the BIM manager/Revit modellers on the two teams, the interviewees were not BIM specialists and had no particular mandate within their respective companies to take any additional responsibility with regard to BIM. It was simply expected that they stay up to date with project delivery tools as part of their normal roles, and in this case BIM was part of the package. A big challenge was the amount of time required to learn to use the necessary tools, and the difficulty of maintaining some degree of aptitude, when they only need to be hands-on very occasionally; "I had good intentions of learning how to use it... You sort of sit down for half an hour with the BIM manager in the office and they show you how to do it, but 3 weeks later when you haven't done it again, you can't. You miss one little step, everything is out the window." (Architect Project 1) The lack of personal capability in using the tools was a frustration for most of the interviewees, but was only really felt to be a negative factor in the use of BIM when there was a lack of in-house capability.

Most of the issues described are a product of immaturity in the market, and not a fundamental shortcoming in the education or knowledge of the team members. However, the lack of skilled staff is a barrier to the project team's ability to capitalise on the potential benefits of BIM. Although the team leaders do not need to be fully BIM capable, with knowledge or competence in all of the various software tools, they do need to be aware of what tools their teams are using and what can reasonably be expected.

\subsection{Changes to the process}

None of the participants identified specific changes in their design and delivery process that came about as a result of BIM. The biggest difference was increased information exchange, as identified by the Project 2 services engineer: "In terms of liaising with the architect, we would constantly ask the architect, if you do any changes please keep sending us the updated models so that we are up-to-date... we realized that even though they would say it's still a draft model, we would still love to have it. They were happy to give to us." (Services Engineer Project 2) The conversation around design decisions and project progress was described as more open between members of the project team, although the architect for Project 1 considered that this was more a project team decision rather than driven by the use of BIM: "We've always detailed things and resolved things pretty well... I guess from our point of view we were always looking to coordinate all that, it was just happening in a 2D environment, as it has done for hundreds of years." (Architect Project 1) Again, this illustrates that the changes resulting from BIM use on the two projects are less an outcome of the introduction of BIM technology and systems, and more from the communication process that tends to be developed alongside. 
Most participants described BIM as a different way of working rather than identifying specific improvements that BIM delivered. The two most enthusiastic were the Project 2 architect, and the Project 1 site manager, both of whom were experiencing their first BIM project in the cases examined. For the Project 2 architect, the most benefit lay in the way changes could be propagated through a 3D model and from there to the documentation set, so that there was no need to continue updating information in multiple locations: "If you change something or you mark something it's changed and it's updated. The whole thing, the whole model is updated. You don't need to worry, has the elevation been done, or a section, it just happens. That's fantastic, but also with coordination with other consultants, it's just made it so much easier and quicker." (Architect Project 2)

The site manager on Project 1 was also enthusiastic about the level of information and control that BIM offered the construction team, and the way they were able to prototype approaches to construction in the model to plan out the most appropriate strategy; "There were some pretty horrible ceiling corners and things that just had everything going through them, and if you didn't know who was first, you would have been forever pulling the thing down." (Site Manager Project 1)

The architect for Case Study 1, who remained sceptical about the value of BIM to the design team, did not consider that it added value, but equally did not feel that there was any disadvantage to using the 3D approach and associated information modelling capabilities in the design and construction process. From his perspective it was a change for the sake of change, whereas the existing processes served the purpose equally well; "You still need to do the old-fashioned things like meet once a fortnight and sit down with a pen and paper and ... you know? What height are you having that beam and what clearance do you need under there for the duct work and ... it's not as if the model kind of solves any of that for you." (Architect Project 1) In addition, he considered that the division of modelling skills within the company created a barrier between the design and documentation elements which hampered the architectural process.

In contrast, the services engineer on Project 2 considered that the use of BIM offered little change to the end design but delivered an advantage because of the quality control stages it added into the process. In his view, the fact that the engineer did not have the BIM skills became an advantage purely because they did not work directly in the modelling tools; "Having to do it on a paper and giving it to another person to look at the paper and draw it, it's almost like a QA. He's checking my work, so if we skip that it means we lose another channel of checking... I think it is more heavily policed when it comes to a BIM project because it does go out in 3D... It has to make a lot of sense. Everyone is carrying responsibility." (Services engineer Project 2).

Disadvantages identified were largely in the area of skills, as previously described, but also related to being effectively the frontrunners within the local industry and having to make it up as they went along. For the architects on Project 1, where this was the first BIM project they had been involved with, this was felt quite keenly: "We are like the pioneers here in our office. We can't really learn from others in the office, so we do need to look outside the office for more knowledge and these theories." (Architect Project 2)

Several respondents identified that the time commitment in the case study projects was greater as a result of the BIM framework, though all except the Project 1 architect acknowledged that this was a result of the experimental nature of their BIM implementation to date, and likely to improve as they became more experienced in the software tools and associated processes. 


\subsection{Challenges}

The main challenges arising on both projects were to do with agreeing project norms and establishing the base line details for managing the information and exchange processes. Some of the difficulties described are quite fundamental issues. For example, the services engineer on Project 2 described a degree of confusion early on in the project because of different versions of software in use between the engineers and the architects.

Project 1 was effectively a follow-up to a previous project involving most of the same project partners, on which a limited BIM implementation was used. The benefits of learning from that first project were described by most of the participants, and included aspects such as the software issues raised by Project 2 participants, and other basics such as identifying a common project datum, and establishing lines of communication with modellers as well as designers. It is clear from this that experience is important, but that such experience could equally be transferred in a form such as a simple check list that could be used at the outset of any project to resolve such basic issues. The project partners also transferred experience between members of the project team, with the more experienced helping to guide those who had little or no previous BIM knowledge.

After both of these projects had commenced, the New Zealand BIM Handbook (Building and Construction Productivity Partnership 2014) was released. The more structured process described by that document provides a basis for establishing project norms and clarifying the expectations of the various parties.

\section{CONCLUSIONS}

Both cases are remarkably similar from a BIM perspective, despite the differences in experience, scale of project, and size of the organisations involved. Both teams freely acknowledge the shortcomings of their BIM processes and the distance they have yet to travel before they reach what might be considered an optimal BIM implementation, but they also recognise the improvements that BIM - even in a limited implementation - offers to their individual roles with a project team, and to their projects overall.

What both cases illustrate is that it is not necessary to adopt BIM in an "all or nothing" fashion, but that it is possible to use BIM tools and processes to incrementally improve various aspects of project performance. It is also clear that while skills and knowledge of project participants is important, it is not necessary to transition everyone to a full working knowledge of BIM and for many within the project context awareness of what BIM does, rather than how to use it, is sufficient.

The main challenges seen in both of these projects are not unique to the use of BIM. Issues such as communication, early agreement and involvement of parties, exchange of information, and clearly defined project expectations and responsibilities are all issues on any construction project. Participants in both projects were developing relationships in a BIM context within their own organisations and between project partners, and learning the best ways to manage agreements and spheres of responsibility. Most participants asserted that the connections they had with project partners were still the same as they would have been on a traditional project, but also acknowledged that model exchange had been taking place prior to the move to more complete BIM adoption and that changes had been occurring gradually with that process.

Most of the challenges identified in these case studies are less about BIM but are instead about fundamental communication processes and project relationships within the project team. There seemed to be an expectation, from the client particularly, that the adoption of 
BIM was a magic wand that would automatically deliver superior performance and outcomes. In fact, the processes followed in both case study projects were essentially traditional project delivery pathways.

Future work will focus on the individuals in this process who seek to implement more substantial changes in their company and project environments. As seen with the BIM manager and BIM manager/Revit modeller in these two case studies, BIM specialists tend to take a leadership role in the adoption process and transition to BIM. An investigation of the attitudes, experiences and approaches of a range of BIM specialists will be used to provide a different perspective on BIM implementation and how it is evolving in practice.

\section{REFERENCES}

Blackman, D (2015, 17 April) BIM survey results: Levelling off? Building Digital Edition Retrieved on 12 January 2017 from http://www.building.co.uk/bim-survey-resultslevelling-off?/5074872.article

Building and Construction Productivity Partnership (2014). New Zealand BIM Handbook. The Building and Construction Productivity Partnership: Auckland, NZ. Retrieved on 12 January 2017 from http://www.mbie.govt.nz/about/whatshappening/news/document-image-library/nz-bim-handbook.pdf

Dainty, A., Leiringer, R., Fernie, S., \& Harty, C. (2015). Don't believe the (BIM) hype: The unexpected corollaries of the UK 'BIM Revolution'. In C. Dossick \& G. Macht (Eds) Proceedings of the Engineering Project Organizations Conference, 2015, The University of Edinburgh, Scotland. Retrieved on 12 January 2017 from http://personalpages.manchester.ac.uk/staff/christopher.neilson/files/3B1\%20-\%20Dai nty\%20Leiringer\%20Fernie\%20Harty\%20-\%20BIM\%20Hype.pdf

Davies, R., \& Harty, C. (2013). Measurement and exploration of individual beliefs about the consequences of building information modelling use. Construction Management and Economics, 31(11), 1110-1127. doi: 10.1080/01446193.2013.848994

EBOSS (2015) BIM in New Zealand-an industry-wide view 2015. EBOSS and BIM Acceleration Committee: Auckland, NZ. Retrieved on 12 January 2017 from https://www.biminnz.co.nz/bim-tools/

EBOSS (2016) BIM in New Zealand-an industry-wide view 2016. EBOSS: Auckland, NZ. Retrieved on 12 January 2017 from https://www.biminnz.co.nz/bim-tools/

Fox, S. (2014). Getting real about BIM: Critical realist descriptions as an alternative to the naïve framing and multiple fallacies of hype. International Journal of Managing Projects in Business, 7(3), 405-422. doi:10.1108/IJMPB-12-2013-0073

McGraw Hill Construction (2012). The business value of BIM in North America: Multiyear trend analysis and user ratings (2007-2012). Smart Market Report McGraw Hill Construction: Bedford, MA. Retrieved on 12 January 2017 from http://bimforum.org/wp-content/uploads/2012/12/MHC-Business-Value-of-BIM-inNorth-America-2007-2012-SMR.pdf

NBS (2016) NBS International BIM Report 2016. NBS: Newcastle upon Tyne, UK. Retrieved on 12 January 2017 from: https://www.thenbs.com/knowledge/nbsinternational-bim-report-2016

Smits, W., van Buiten, M., \& Hartmann, T. (2016). Yield-to-BIM: impacts of BIM maturity on project performance. Building Research \& Information, 1-11. doi: 10.1080/09613218.2016.1190579 